\title{
Cutaneous larva migrans syndrome: a case report
}

\author{
Emilia Tekely, Beata Szostakiewicz, Bartłomiej Wawrzycki, Grażyna Kądziela-Wypyska, Maria Juszkiewicz-Borowiec, \\ Aldona Pietrzak, Grażyna Chodorowska
}

Department of Dermatology, Venereology and Peadiatric Dermatology, Medical University of Lublin, Poland Head: Prof. Grażyna Chodorowska MD, PhD

Postep Derm Alergol 2013; XXX, 2: 119-121

DOI: $10.5114 /$ pdia.2013.34164

\begin{abstract}
Cutaneous larva migrans $(\mathrm{CML})$ is a frequent parasitic infestation caused by migration of animal hookworm larvae into the human epidermis. This skin disease is common in warmer climates among people, who have contact with contaminated soil. Clinical manifestation of CML is an itchy, erythematous, linear tract, which appears days to even months after exposure to infested sand or soil. Diagnosis is established on the clinical presentation. We describe a case of CML acquired during a holiday in Brazil.
\end{abstract}

Key words: creeping eruption, cutaneous larva migrans, hookworm infection.

\section{Introduction}

Cutaneous larva migrans (CML) also known as "creeping eruption" is one of the most frequent skin diseases among travelers returning from tropical countries [1-4]. Cutaneous larva migrans is caused by incidental infestation of a human by animal nematode larvae usually thriving dogs and cats [1, 2, 4-16]. The parasites are found mostly in tropical and subtropical regions like the Caribbean, South and Central America, Southern-East Asia and Africa [6, 9, 10, $11,13]$. The most common parasite species causing creeping eruption are Ancylostoma braziliense, Ancylostoma caninum, Necator americanus, Uncinaria stenocephala and Strongyloides stenocephala [5, 7-9, 13, 14]. The parasite infects a human through the penetration of undamaged skin. Commonly affected sites include feet, thighs and buttocks but any part of the body, which has direct contact with contaminated and wet soil e.g. on beaches or in sandpits, can be involved [2, 4, 6, 10, 12-16]. Nematode larvae in an incidental human host do not complete their full life cycle, but stay confined to the epidermis and less often the upper dermis [1, 2, 4, 5, 7-11, 13-15]. The parasite migrates at the rate of a few millimeters to a few centimeters per day forming a tortuous, serpiginous tunnel rising above the skin surface with a length of a few to even more than $10 \mathrm{~cm}$ $[3,6-8,12-14,17]$. The parasite migration causes severe pruritus, which often leads to epidermal damage and secondary infections [1-7, 10,11,13,14]. Initially, at the site of parasitic penetration a red itchy papule may be noticed, which with time raises above the skin surface [10, 13, 14]. As the larva migrates a linear wandering erythema, that is clearly separated from its surrounding, appears [1-3, 6, $8,11,13]$. The tunnels left by the migrating parasite desiccate and are covered with a scab [13]. It is worth noticing that the nematode may survive in the skin for many months $[2,4,5,10,12,14]$.

We report a case of cutaneous larva migrans on the right foot, in a 2-year-old Polish girl, who returned from a trip to Brazil.

\section{Case report}

A 2-year-old girl was presented to our Department in May 2011 because of linear wandering erythema, which appeared on the girl's right heel. A few days earlier the girl's mother had noticed an itchy reddened spot in the form of a papule on the right foot. The lesion had been rapidly increasing in size forming a serpiginous erythema and pruritus had become more intense. Examination revealed a slightly raised erythematous serpentine lesion and a local edema on the right foot (Figures 1 and 2). During the examination, the patient's mother informed us of their recent trip to a hot zone country (Brazil) from which they had returned a week before. 


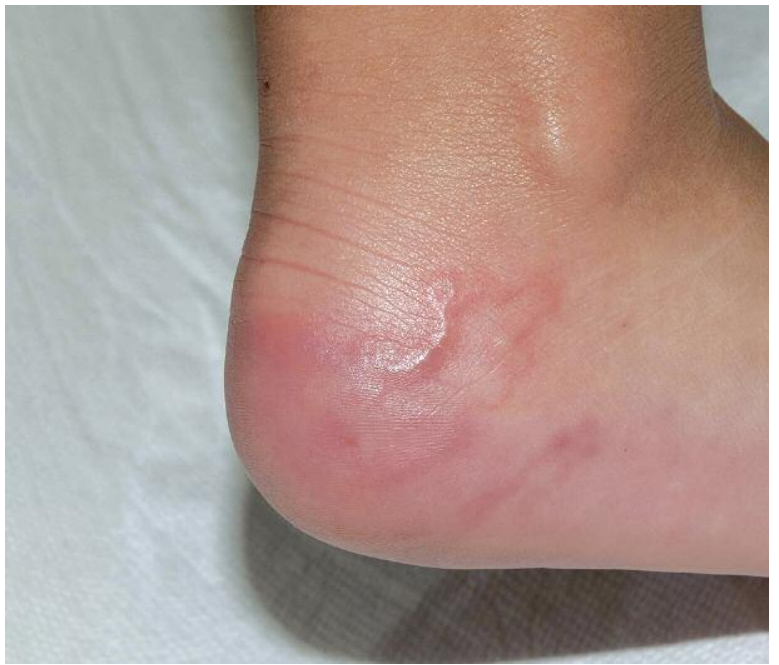

Figure 1. Linear wandering erythema on the right heel

Peripheral blood analysis and total IgE level were within normal ranges. Parasitological examination of feces was negative. The location and characteristic presentation of linear serpiginous skin lesions on the right foot as well as the patient's stay in the South America made it possible to diagnose her with cutaneous larva migrans syndrome. The girl was also referred to the Outpatient Clinic of Child Infectious Diseases, where the diagnosis of CML was confirmed.

The patient was treated with oral albendazole $(200 \mathrm{mg} /$ day for 3 days) and freezing the leading edge of the cutaneous track with solid carbon dioxide. Due to severe pruritus the girl received also oral and topical antihistamine drugs, i.e. desloratadine $(2.5 \mathrm{mg} /$ day for 3 days $)$ and dimetindene applied on her right foot. A few hours after the freezing session numerous wheals were noticed and therefore the patient received dexamethasone i.m. for 3 consecutive days. The lesion totally disappeared within a few days after treatment was initiated.

\section{Discussion}

One of the most frequent helminthic infections among travelers returning from tropical and subtropical regions of the world is cutaneous larva migrans. This tropically acquired dermatosis was described for the first time in the $19^{\text {th }}$ century [14]. Cutaneous larva migrans is caused by accidental, percutaneous migration of animal hookworm larvae within the human skin. Ancylostoma braziliense is one of the most common species in tropical and subtropical regions, which affects people of all ages. Lesions are located on the feet, legs and buttocks in the adults while children can be infected also on the genitals and hands [16]. In most instances, the skin areas, which have direct con-

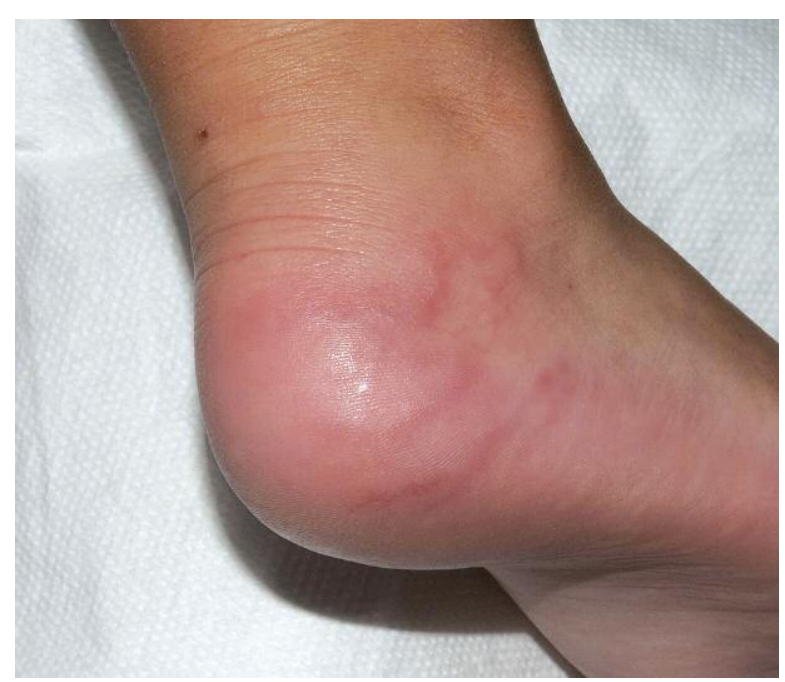

Figure 2. Local edema with slighty raised erythematous serpentine lesion on the right foot

tact with soil or sand contaminated by feces of infected animals are affected. In a warm, humid environment, nematode larvae can survive and be infective for several weeks or even several months. Due to the fact that humans are accidental hosts the parasites are unable to complete their life cycle. The larvae secrete protease and hyaluronidase, which facilitate the penetration through epidermis to achieve internal organs $[4,7,14]$. Hence, a raised, pruritic, erythematous, linear track, which appears usually a few days after infestation, is a typical clinical manifestation. In most cases, the diagnosis of cutaneous larva migrans is based on the typical skin findings and the previous travel history with a real possibility of exposure [2, 3, 6, 8, 14-16]. One should be aware of the presence of atypical clinical presentation of CML. This knowledge can prevent misdiagnosis, which often leads to insufficient or delayed treatment.

Uncommon clinical presentations of $\mathrm{CML}$ include [2, 4, 13, 14, 17]:

- hair follicle inflammation known as "hookworm folliculitis" most frequently in the buttocks area,

- diffuse multifocal papulo-vesicular eruption localized mainly on the chest, back and abdomen,

- migrating urticaria.

The complications of cutaneous larva migrans include secondary bacterial infections, local or general allergic reactions and very rarely parasite's migration to internal organs $[2,7,10,11,13]$.

Effective treatment of hookworm-related CML is based on oral or topical antihelminthics. Ivermectin, albendazole and tiabendazole are drugs, which are acceptable for systemic treatment. First-line treatment are ivermectin and albendazole. Ivermectin is well tolerated and highly effective but contraindicated in children younger than 5 years 
[14]. It is taken at a single dose of $200 \mu \mathrm{g} / \mathrm{kg}$, while the average dose is $12 \mathrm{mg}$. Albendazole is also efficient at a daily dosage between $400 \mathrm{mg}$ and $800 \mathrm{mg}$ for 1 to 7 days. Thiabendazole is not recommended because of a relatively high incidence of the following side effects: dizziness, nausea, vomiting and intestinal cramps $[6,7,14]$. In cases when oral drugs are contraindicated, ointments with $10 \%$ albendazole or $10-15 \%$ thiabendazole should be considered [18]. Topical application of ointment 3 times daily for 5 to 10 days on the affected skin is comparable to the oral treatment for CML $[14,18]$. Nowadays, physical modalities such as cryotherapy with carbon dioxide or liquid nitrogen are used in exceptional cases $[1,8,11,13,15]$. The response to an antihelmintic drug and rapid resolution of the lesion confirmed the initial diagnosis of cutaneous larva migrans $[13,15]$.

Traveling has become accessible and universal among people in the world leading to an increase in the number of tropical dermatosis e.g. cutaneous larva migrans. Nowadays, health education should be focused on tourists, who are planning a trip to hot zone countries, endemic areas for CML. They should be advised to wear shoes in sandy areas, to use deckchairs or mattresses on beaches and to avoid beaches where animals are present.

\section{References}

1. Caumes E. Treatment of cutaneous larva migrans. CID 2000; 30: 811-4.

2. Perman MJ. 10-year old boy present with a pruritic, blistering eruption. Infectious Disease News 2010; 23: 18.

3. Gutte R, Khopkar U. Cutaneous larva migrans (creeping eruption). Indian Dermatol Online J 2011; 2: 48.

4. Malvy D, Ezzedine K, Pistone T, et al. Extensive cutaneous larva migrans with folliculitis mimicking multimetameric herpes zoster presentation in an adult traveler returning from Thailand. J Travel Med 2006; 13: 244-7.

5. Jackson A, Heukelbach J, Calheiros CML, et al. A study in a community in Brazil in which cutaneous larva migrans is endemic. CID 2006; 43: 8-13.

6. Lesniak R. Cutaneous larva migrans. Dermatol Nurs 2008; 6 : 471-2.

7. Blackwell V, Vega-Lopez F. Cutaneous larva migrans: clinical features and management of 44 cases presenting in the returning traveler. Br J Dermatol 2001; 145: 434-7.

8. French SJ, Lindo JF. Severe cutaneous larva migrans in traveler to Jamaica, West Indies. J Travel Med 2003; 10: 249-50.

9. Kienast A, Bialek R, Hoeger PH. Cutaneous larva migrant in northern Germany. Eur J Pediatr 2007; 166: 1183-5.

10. Yavuzer K, Ak M, Karadag AS. A case report of cutaneous larva migrans. EAJM 2010; 42: 40-1.

11. Watkins J. Cutaneous larva migrans: diagnosis and management. British Journal of School Nursing 2009; 7: 325-7.

12. Siriez JY, Angoulvant F, Buffet P, et al. Individual variability of the cutaneous larva migrans (CML) incubation period. Pediatr Dermatol 2010; 2: 211-2.

13. Kacprzak E, Silny W. Cutaneous larva migrans syndrome in travelers returning from warm climate countries. Postep Derm Alergol 2004; XXI: 24-9.

14. Heukelbach J, Feldmeier H. Epidemiological and clinical characteristics of hookworm-related cutaneous larva migrans. Lancet Infect Dis 2008; 8: 302-9.
15. Roest MAB, Ratnavel R. Cutaneous larva migrans contracted in England: a reminder. Clin Exp Dermatol 2001; 26: 389-90.

16. Black MD, Grove DI, Butcher AB, et al. Cutaneous larva migrans in infants in the Adelaide Hills. Australas J Dermatol 2010; 51: 281-4.

17. Veraldi S, Bottini S, Carrera C, et al. Cutaneous larva migrans with folliculitis: a new clinical presentation of this infection. JEADV 2005; 19: 628-30.

18. Caumes E. Efficacy of albendazole ointment on cutaneous larva migrans in 2 young children. CID 2004; 38: 1647-8. 